\title{
Germany's rectors call for pay by results
}

[MUNICH] A proposal by German university chiefs that the pay of academics should be based on performance has caused controversy in the academic community.

Such a system would promote competition between both academics and universities, says the German University Rectors Conference (Hochschulrektorenkonferenz; HRK). It would also allow universities to offer industrial-level salaries to attract particularly talented scientists.

But the German Association of Universities, a lobby organization representing 17,000 professors, has reacted angrily to the proposal. Its president, Hartmut Schiedermair, describes the suggestion as "incredible" and directly against the interests of professors, as it could dramatically reduce the income of the next generation of academics.

The rectors have recommended that current increments related to age and family size should be eliminated. Instead the basic salary should be roughly equivalent to a middle grade of professor, currently around DM8,700 (US\$5,100) a month. Increments would be calculated on the basis of research and teaching performance.

In presenting the proposal at the HRK general assembly last month, Klaus Landfried, president of the organization, admitted that, if it is adopted, "many people will start off with less money than today".

Starting salaries should be negotiated between universities and individual candidates, says Landfried. Universities would then be able to use their personnel budgets flexibly, rather than being obliged to comply with centrally fixed salary scales.

The proposal is supported by the new Social Democrat minister for education and research, Edelgard Bulmahn. In fact, such a pay reform is part of the new red-green government's coalition agreement. "Extensive modernization of employers' rights is of fundamental significance for the future of our universities," Bulmahn said in her inaugural speech to the German parliament last month.

But Schiedermair, speaking for the German Association of Universities, says that the proposals are particularly unfair because university teachers have had to cope with many more students in the past two decades, yet have still managed to maintain high research standards.

Moreover, he strongly objects to the

\section{Software fix for Gallieo may salvage data}

[WASHINGTON] US space engineers are working to correct minor problems with the Galileo spacecraft that have ruined observations of Jupiter's icy moon Europa during two of the probe's last three fly-bys. The last of Galileo's close encounters with Europa is scheduled for February.

During the most recent fly-by on 22 November, the spacecraft unexpectedly went into a protective 'safe' mode just before passing the moon at a distance of 2,300 kilometres. This prevented it from taking photographs and gathering data.

Galileo project scientist Torrence Johnson of the Jet Propulsion Laboratory in Pasadena, California, says the most likely culprit is increased radiation when the spacecraft's highly elliptical orbit brings it close to the giant planet. Galileo, which left Earth in 1989 and arrived at Jupiter six years later, has already taken 150 per cent of the radiation dose for which it was designed.

Having completed its primary mission last December, the spacecraft was given a two-year extension to gather more data on Europa, study the torus of charged particles associated with Jupiter's satellite Io, and make two close fly-bys of that volcanic moon next autumn.

Europa is a high-priority target for the US space agency NASA, which plans to send a follow-on mission early in the next decade to help decide the question of whether an ocean lies beneath the satellite's icy crust. The problems with Galileo mean that some of the moon's surface will not be photographed at high resolution as planned.

But Johnson says some high-priority observations may be made by rescheduling targets to be viewed during the final fly-by, as was done after a short-circuit from a piece of space debris led to the loss of Europa data from an encounter last July.

Project engineers are working on a software fix that would in effect tell Galileo to ignore circumstances that trigger the protective mode during close encounters. This is not likely to be ready by February, however, so the last fly-by may meet the same problem.

The strategy is also risky because it is akin to disconnecting an alarm. But the extended mission was always planned to be riskier, says Johnson.

Hoping that the spacecraft survives the high-radiation environment around Io next year, project scientists are drawing up a proposal to NASA for another one-year extension. That would allow Galileo to make coordinated observations with the Saturn-bound Cassini spacecraft when it flies through the Jupiter system in December 2000.

Tony Reichhardt

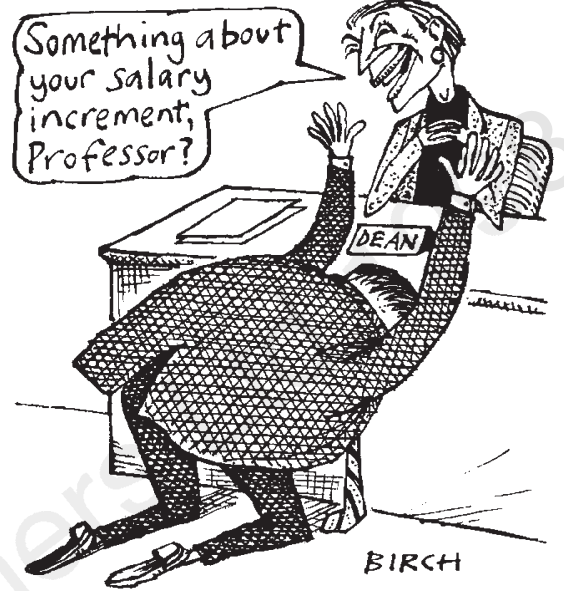

HRK's suggestion that the same basic salary should be applied to teachers at Fachhochschule, the vocationally orientated higher-education institutes which have lower qualification requirements than universities.

Some rectors agree. The proposal "has triggered considerable anger among the professors at our university", says Jens Peter Meincke, a lawyer and rector of the University of Cologne.

The HRK also proposes abolishing civil servant (Beamter) status, equivalent to tenure, for professors. But critics of this suggestion argue that tenure is a necessary incentive for scientists whose early careers, based on short-term contracts, are difficult, poorly paid and risky. "The Beamter status has a long tradition, and the security it offers is important to ensure the independence of professors," says Meincke.

The German Association of Universities is also concerned whether research and teaching performance can be assessed fairly. The HRK says assessment should be based on reliable indicators such as number of research publications, amount of external research funds, prizes and awards, number of examinations set and results of teaching evaluation by students.

But the association says that it is wary of giving control of salary increments exclusively to deans or rectors. They say that although such criteria are objective, additional subjective factors would always play a role in evaluations.

The salary debate has overshadowed other recommendations in the HRK's proposal. These include the call for universities to abandon Habilitation, the high-level but time-consuming postdoctoral qualification officially required to become a professor.

The rectors also call for more flexibility in the career structure of technical staff, enabling the best technicians to be rewarded financially. These recommendations have prompted no response from the academic community.

TilmannKiessling 